\title{
Performance Analysis of MAC Layer Protocols in Wireless Sensor Network
}

\author{
Hameeza Ahmed, Muhammad Khurram \\ Department of Computer \& Information Systems Engineering, NED University of Engineering \& Technology, Karachi, \\ 75270, Pakistan. \\ Email: hameeza@neduet.edu.pk,mkhurrum@neduet.edu.pk
}

\begin{abstract}
Media Access Control (MAC) layer protocols have a critical role in making a typical Wireless Sensor Network (WSN) more reliable and efficient. Choice of MAC layer protocol and other factors including number of nodes, mobility, traffic rate and playground size dictates the performance of a particular WSN. In this paper, the performance of an experimental WSN is evaluated using different MAC layer protocols. In this experiment, a WSN is created using OMNeT++ MiXiM network simulator and its performance in terms of packet delivery ratio and mean latency is evaluated. The simulation results show that IEEE 802.11 MAC layer protocol performs better than CSMA, B-MAC and IEEE 802.15.4 MAC layer protocols. In the considered scenario, IEEE 802.15.4 is ranked second in performance, followed by CSMA and B-MAC.
\end{abstract}

Index Terms-OMNeT++, MiXiM, Wireless Sensor Network, MAC Layer Protocols, Mobility.

\section{INTRODUCTION}

A typical Wireless Sensor Network (WSN) monitors environmental conditions by using spatially distributed autonomous sensors. WSN applications lay in the fields of energy control system, environmental monitoring, security and surveillance, health application, area monitoring and many more [1]. A WSN can be a composite of hundreds to thousands of sensor nodes. Each node contains an environment sensor unit, an Analog to Digital Converter (ADC), a Central Processing Unit (CPU) running host software, a power unit and a wireless/radio communication unit [2]. As a WSN can grow in large size containing thousands of these units, infield testing of such a large network becomes practically expensive and troublesome. Scientists and engineers have been using efficient simulation tools to design and analyze WSNs beforehand [3]. In this regard, various simulation tools are being used while performing research in this field [4], [5]. Some examples of such WSN simulation tools are OMNeT++, TOSSIM, Avrora, NS22, NS-3, EmStar, J-Sim, ATEMU, QualNet, TinyOS, OPNET, NetSim, SimPy etc.

The performance of a typical WSN is not the same on different MAC layers [11]. A WSN is implemented considering various design factors like mobility of the nodes, playground size, number of nodes, traffic rate and most importantly MAC layer protocol. It may happen that a particular WSN on a selected MAC layer protocol performs really well at the beginning, but as the factors like the number of nodes, mobility of the nodes and traffic rate are varied the performance would drop. Therefore, the design factors should be carefully adjusted while realizing a particular WSN. OMNeT++ with MiXiM makes it easier for the designer to plan and test a WSN, varying multiple factors and see which MAC layer protocol delivers better than others.

In literature, several WSN design studies have been reported by academia and industrial communities. An experiment is conducted with NS2 simulator that compared the performance between IEEE 802.15.4 and IEEE 802.11 in [6]. The results show that the IEEE 802.15.4 protocol performs more efficiently in terms of resource utilization and control overhead as compared to IEEE 802.11, in a non-beacon enabled mode. Similarly, a performance analysis of IEEE 802.15.4, IEEE 802.11, and S-MAC is presented in [7], which indicates IEEE 802.15.4 performs better in terms of latency and energyconservation as compared to S-MAC. In [8], a comparison is made between CSMA and IEEE 802.11. The coexistence between IEEE 802.15.4 and IEEE 802.11 is addressed along with simulation results in [9]. IEEE 802.15.4 performance has been analyzed using OMNeT++ in [10]. This paper also includes analysis of scalability problem and payload sizes effect on IEEE 802.15.4.

In this paper, four different MAC layer protocols are evaluated. These include IEEE 802.11, IEEE 802.15.4, CSMA, B-MAC. OMNeT++ MiXiM simulator is used to conduct this experiment. The performance of different MAC layer protocols in a WSN is studied by varying multiple factors including mobility of the nodes, number of nodes, traffic rate etc. In this paper, section-II discusses different MAC layer protocols. In Section-III, multiple factors affecting WSN performance and performance matrices are described. Section-IV shows simulation and results are given in section- $\mathrm{V}$ followed by section -VI giving the conclusion.

\section{MAC LAYER PROTOCOLS}

MAC layer provides the reliability and efficiency for WSN [11], [35], [36]. It is responsible for channel access policies, scheduling, buffer management and error control. 
As per OSI model, shown in Fig. 1, MAC layer is a sublayer of the data link layer (DLL) [12]. It handles channel access, frame-level error prevention, detection and correction. A MAC protocol provides framing, medium access, reliability, flow control, and error control [13]. MAC protocol regulates access to the shared medium by which application performance requirements are satisfied [14].

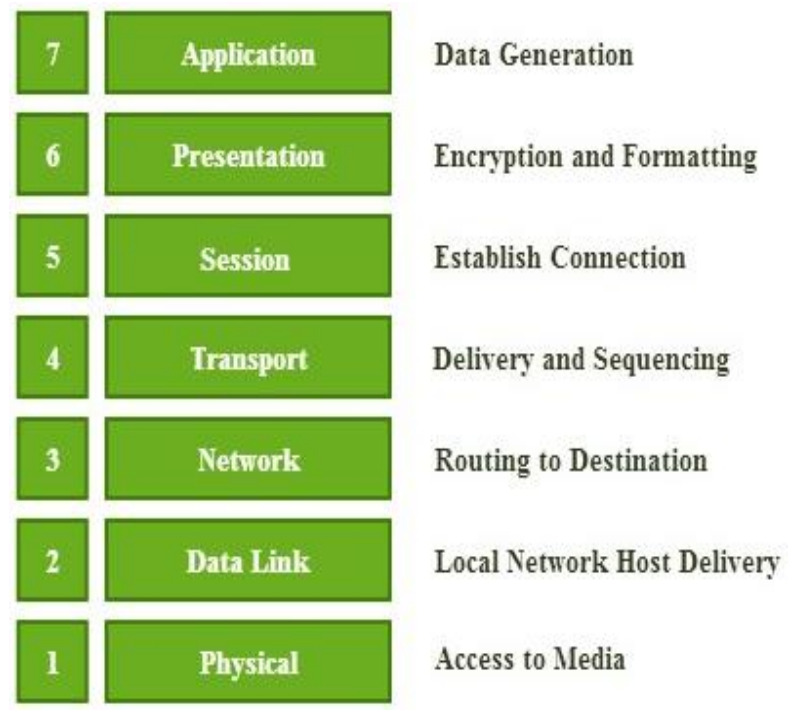

Fig. 1. Network OSI model with 7 layers in descending order

In WSN systems, different MAC layer protocols are used [13]. Some of the popular MAC layer protocols are briefly discussed as follows.

\section{A. CSMA and CSMA/CA}

Carrier Sensed Multiple Access (CSMA) is a random access protocol to control access to the network. Devices attached to the network first sense the channel and then transmit if and only if they get an empty channel otherwise if the channel is busy devices attempt to wait. It is widely adopted in wireless networks due to its simplicity and distributed nature [15]. In Carrier Sense Multiple Access/Collision Avoidance (CSMA/CA) technique a node signals its intent to transmit earlier which results in collision avoidance. Due to excessive overhead this technique is not so famous [16].

\section{B. IEEE 802.11}

This technique is contention based medium access control protocol for implementing wireless local area network (WLAN). It avoids collisions in data packets through carrier sensing and randomized back-offs techniques. Its main characteristics include simplicity, flexibility and cost effectiveness [17], [18].

\section{IEEE 802.15.4}

This technique is uniquely designed for low rate wireless personal area networks. It focuses on low data rate, low power consumption and low cost wireless networking and offers device level wireless connectivity.
It can benefit different applications such as those using sensors that control lights or alarms, wireless computer peripherals, wall switches that can be moved at will, inventory tracking devices etc [6].

\section{D. $B-M A C$}

Berkeley MAC (B-MAC) protocol is widely used in WSNs. This protocol uses adaptive preamble sampling scheme in which medium is sampled at fixed time intervals. BMAC focuses on effective collision avoidance, efficient channel utilization and low power operation [19], [20].

\section{E. Aloha}

In Aloha, a transmitter can send packet at any time without coordinating between nodes. Pure aloha, slotted aloha and aloha with preamble sampling are used as aloha protocols [21].

\section{F. LMac}

Lightweight Medium Access (LMAC) protocol allows each node to select a timeslot from its one-hop neighbors using slot occupancy information [22].

\section{Performance AfFecting FaCtors AND PERFORMANCE MATRICES}

\section{A. Multiple Factors}

Some of the factors that influence performance of a MAC layer protocol in a Wireless Sensor Network (WSN) are mentioned below.

Mobility: With the recent developments WSNs are not just stationary but they provide mobility as well [23]. They are referred as "mobile sensor networks" such as moving robots, surveillance aircrafts. With the mobility in consideration the performance of a WSN is certainly affected.

Traffic Rate: Traffic is another important factor in network performance.

Number of Nodes: It is not always the same; it may differ in different scenarios which affects the network performance.

Playground Size: It is the size of area where nodes reside.

\section{B. MAC Performance Matrices}

In order to design good MAC layer protocol [17] for WSN attributes such as energy efficiency, latency, throughput, fairness are needed to be considered. We mainly observe MAC layer performance for a WSN with respect to 2 attributes.

Packet Delivery Ratio: The number of packets received at the destination to the number of packets sent at the source [17].

Mean Packet Latency: The time taken by the packet to reach to the destination node is averaged for all the packets [17]. 


\section{SIMULATION}

\section{A. Simulation with $O M N e T++$ and MiXiM}

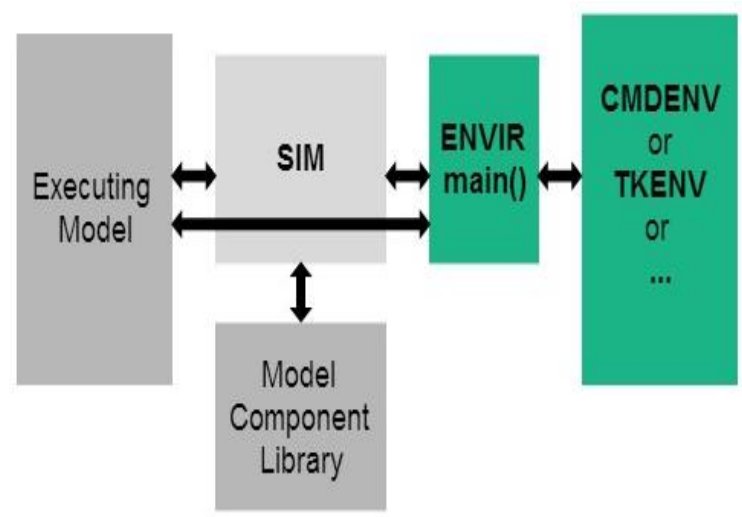

Fig. 2. Architecture of OMNeT++ Simulation Programs

OMNeT++ is an extensible, modular, open source $\mathrm{C}++$ discrete event simulation environment. It is used for building simulators for wired and wireless communication networks, on-chip networks, queueing networks etc, by the designers and engineers. The architectural block diagram of $\mathrm{OMNeT}++$ simulation environment is given in Fig. 2. There are 5 major components in OMNeT++ simulation program. Sim is the simulation kernel and class linked library responsible for module instantiations and building concrete simulation model. The Model Component Library contains code implementations for simple and compound modules. The user interface libraries (Envir, Cmdenv and Tkenv) provide an environment for simulation execution. The Executing Model contains objects that are instances of model component library components. This model is set up for simulation [33], [34]. OMNeT++ is appropriate for studying WSNs both with networking and distributed systems aspects. It is simpler to use due to an Eclipsebase integrated development environment (IDE) and extensive graphical user interface (GUI) support. OMNeT++ also makes it feasible to create and configure models, to perform batch executions, and analyze simulation results [24], [25], [26]. MiXiM is an OMNeT++ modeling framework, which is created for mobile and fixed wireless networks (WSNs, ad-hoc networks, body area networks, vehicular networks, etc). It offers detailed models of wireless MAC protocols, radio wave propagation, radio transceiver power consumption, and interference estimation. It extends OMNeT++ functionality by providing detailed models of the wireless connectivity, wireless channel, models for obstacles, mobility models, and many communication protocols especially at the Medium Access Control (MAC) level [27], [28].

A project that is created in MiXiM framework \& OMNeT++ contains various files namely NED (network description) file, XML file, INI (initialization) file. The NED file allows the user to describe the structure of a simulation model in the NED language [29]. It lets the user to create compound modules via simple modules.
While working with MiXiM, the file Network.ned contains the simulation network including the number of nodes and their nodes types [30]. Similarly, the Host.ned contains the compound module defining the nodes for the network [30]. It tells what will be the type of network layer, transport layer, session layer, presentation layer, application layer; mobility module, address resolution module and MAC layer as shown in Fig. 3. The file Nic.ned contains the compound module, which defines the network interface card of the hosts [30]. MAC layer type is mentioned in this file as shown in Fig. 4.

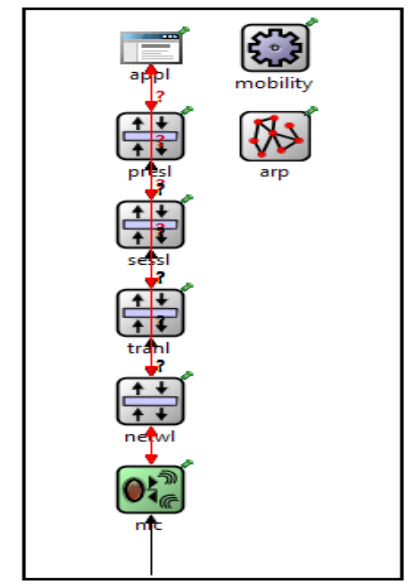

Fig. 3. Node Structure

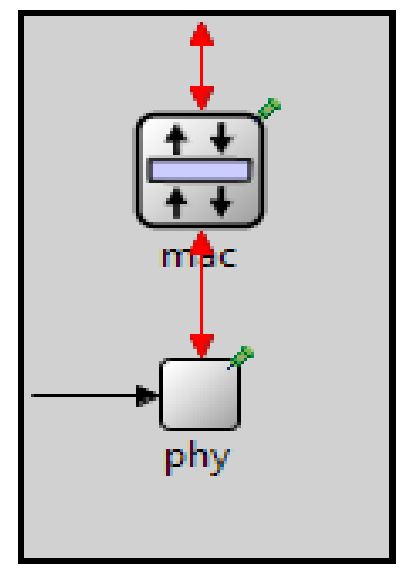

Fig. 4. NIC Structure

The omnetpp.ini file allows the user to configure simulation models for execution [30]. It allows the user to specify simulation parameters, world utility parameters, parameters for the connection manager and parameters for the host. The parameters for the host include physical parameters, MAC layer parameters, application layer parameters, network layer parameters and mobility parameters. The config.xml file contains configuration for the physical layer's decider and analogue models [30]. Due to object oriented programming modular approach, it gets easier to work in MiXiM as the work is divided into different files.

MiXiM provides various MAC layer protocols including Aloha, B-MAC, L-MAC, CSMA, IEEE 802.15.4 and IEEE 802.11 [28]. Aloha is implemented in AlohaMacLayer class, which is inherited from 
UWBIRMac. B-MAC and L-MAC are implemented in BMacLayer and LMacLayer classes respectively; both are inherited from BaseMacLayer [19]. IEEE 802.11 is implemented in Mac80211 class, which is inherited from BaseMacLayer. IEEE 802.15.4 is implemented in CSMA802154 class, which is inherited from csma [31]. We have two more classes namely csma and CSMAMacLayer both are inherited from BaseMacLayer and implement CSMA protocol. CSMAMacLayer implements non-persistent CSMA. csma is generic and it supports linear, constant, exponential backoffs and MAC ACKs [32]. MiXiM also provides different mobility models like constant speed, rectangular, circular mobility to model mobile scenarios. In order to adjust traffic rate MiXiM gives an attribute trafficparam. With periodic traffic, trafficparam is the constant time interval in seconds. As this time interval is decreased, performance degrades due to more loads. MiXiM can support simulations with up to 1000 nodes [23]. MiXiM uses a parameter called playground size to set the size of area.

\section{B. Simulation Parameters and Experimental Setup}

The experiment is performed on OMNeT++-4.3.1 version along with MiXiM-2.3 framework. In order to test MAC layer protocols a wireless sensor network is constructed with MiXiM. After this, various parameters are specified in omnetpp.ini file. These parameters, shown in Table 1, include total number of nodes, mobility, source node, destination node, traffic rate, network type, application type, playground size. Physical layer parameters including analogue models and decider type are mentioned in config.xml file. MAC type is mentioned in Nic.ned file. After initial configurations, the simulation is run and matrices including packet delivery ratio and mean latency are observed which help in performance analysis.

\section{OBSERVATIONS AND RESULTS}

Initially, the simulation is run with stationary nodes and later the same setup is simulated with mobile nodes. This leads to an observation that as mobility of the nodes increases the average packet delay increases [23]. In addition, traffic increase also degrades performance. The WSN is tested with 4 different MAC layer protocols namely IEEE 802.154, IEEE 802.11, B-MAC and CSMA. This paper only focuses on the impacts caused by 2 factors i.e. number of nodes and traffic param, on MAC layer protocols and on the overall mobile WSN performance.

With this experiment one can observe how each MAC layer performs with this WSN. Bar charts in Fig. 5 and Fig. 6 are representing bars for packets received count and mean latency when number of nodes are 10, discussed in Table 2. Fig. 7 and Fig. 8 display the metrics for 25 nodes, discussed in Table 3. Similarly, Fig. 9 and Fig. 10 show the results for 50 nodes discussed in Table 4. The input axis in the bar charts represents packets sent count and traffic param in microseconds. Packets sent count is $0.1 \mathrm{~K}, 0.5 \mathrm{~K} \& 1 \mathrm{~K}$ for each traffic param. The traffic param are 100000 microseconds, 5000 microseconds \& 1 microsecond. There are total 4 output bars for 1 input. Each bar represents result of a particular MAC layer protocol in a specified situation. Obviously packets received count is good when the bars are larger and in case of latency the bars need to be shorter. In Table 2, Table 3 and Table 4 MAC layer evaluation is performed by taking average of all the outcomes of a selected MAC layer protocol at a particular traffic param. It can be seen clearly how IEEE 802.11 dominates others both in packets received count and mean latency.

Table 1. Simulation Parameters

\begin{tabular}{|c|c|c|c|c|}
\hline \begin{tabular}{|l|} 
No of hosts \\
\end{tabular} & \multicolumn{4}{|l|}{$10,25,50$} \\
\hline Application Type & \multicolumn{4}{|l|}{ Sensor App Layer } \\
\hline Network Type & \multicolumn{4}{|l|}{ Flood } \\
\hline Source Node & \multicolumn{4}{|l|}{0} \\
\hline Destination Node & \multicolumn{4}{|l|}{$9,24,49$} \\
\hline Traffic Type & \multicolumn{4}{|l|}{ Periodic } \\
\hline Mobility Type & \multicolumn{4}{|l|}{ ConstSpeedMobility } \\
\hline Mobility Speed & \multicolumn{4}{|l|}{$1 \mathrm{mps}$} \\
\hline Mobility Update Interval & \multicolumn{4}{|l|}{0.1 seconds } \\
\hline Source Mobility $(\mathbf{x}, \mathbf{y})$ & \multicolumn{4}{|l|}{$(0 \mathrm{~m}, 0 \mathrm{~m})$} \\
\hline Destination Mobility(x,y) & \multicolumn{4}{|l|}{$(300 \mathrm{~m}, 300 \mathrm{~m})$} \\
\hline Playground Size(x,y) & \multicolumn{4}{|l|}{$(300 \mathrm{~m}, 300 \mathrm{~m})$} \\
\hline Traffic Param & \multicolumn{4}{|c|}{ 0.1 Seconds, 0.005 Seconds, 0.000001Seconds } \\
\hline No of Packets sent at source & \multicolumn{4}{|l|}{$100,500,1000$} \\
\hline MAC Type & $\begin{array}{l}\text { CSMA802154 } \\
\text { 802.154) }\end{array}$ & csma (CSMA) & BMacLayer (B-MAC) & $\begin{array}{l}\text { Mac80211 (IEEE } \\
\text { 802.11) }\end{array}$ \\
\hline Decider Type & Decider802154Narrow & SNRThresholdDecider & SNRThresholdDecider & Decider80211 \\
\hline
\end{tabular}




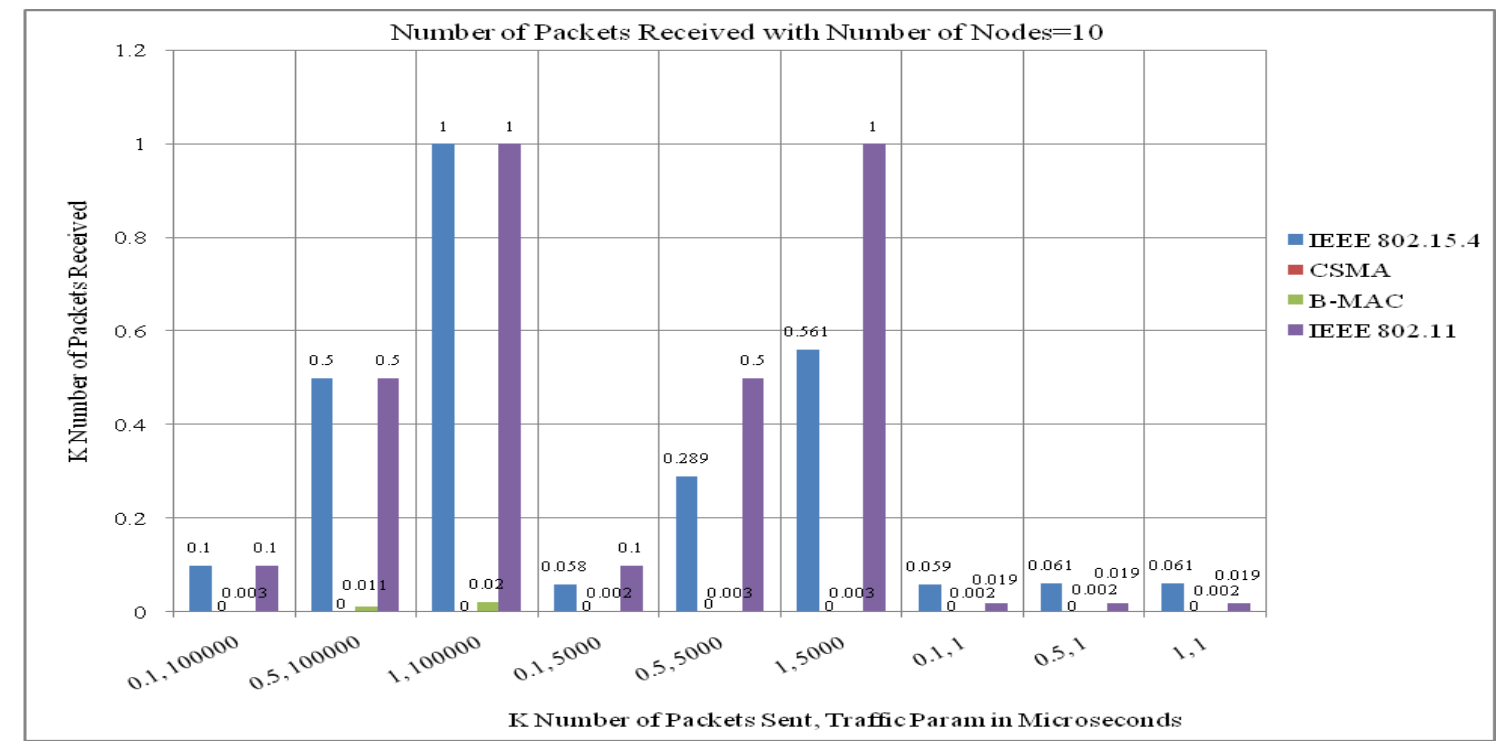

Fig. 5. K Number of Packets Received with each 4 MAC Layer Protocols at 10 Nodes

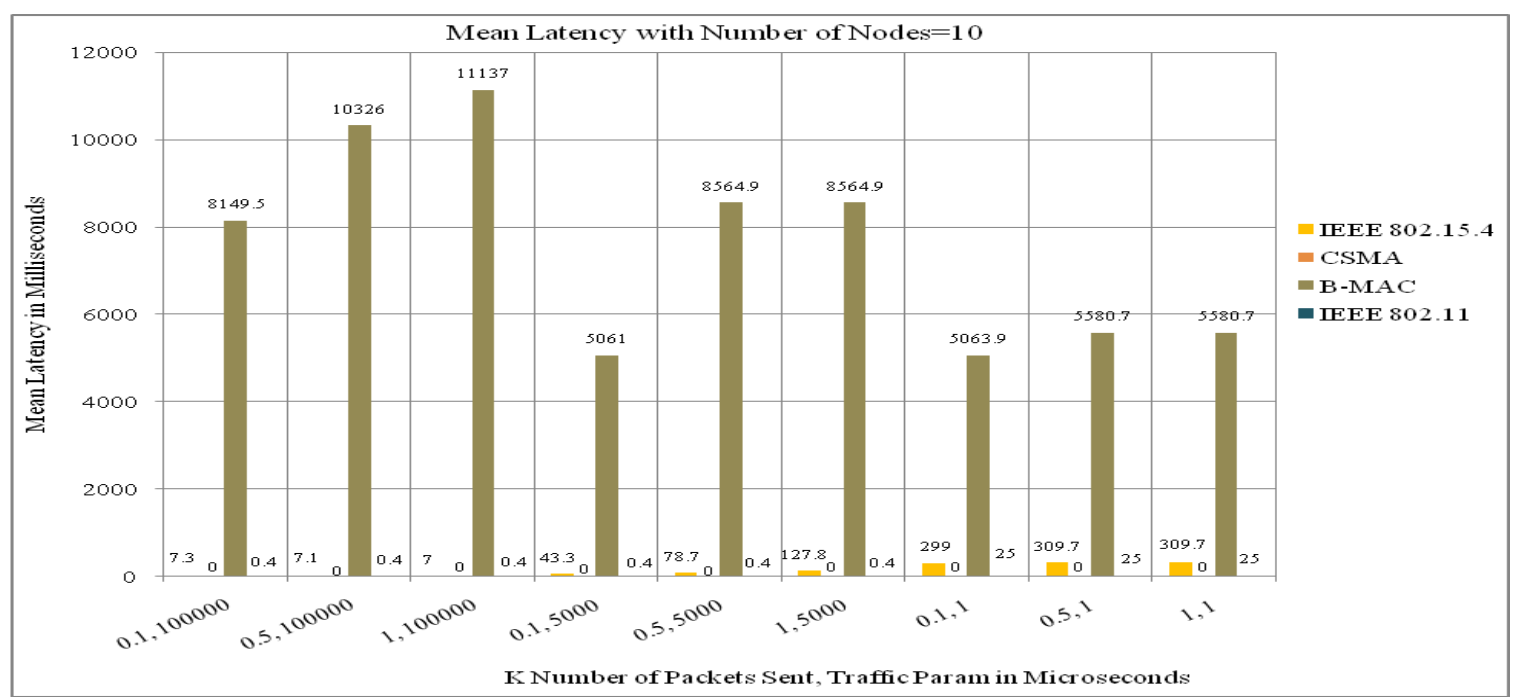

Fig. 6. Mean Latency in Milliseconds with each 4 MAC Layer Protocols at 10 Nodes

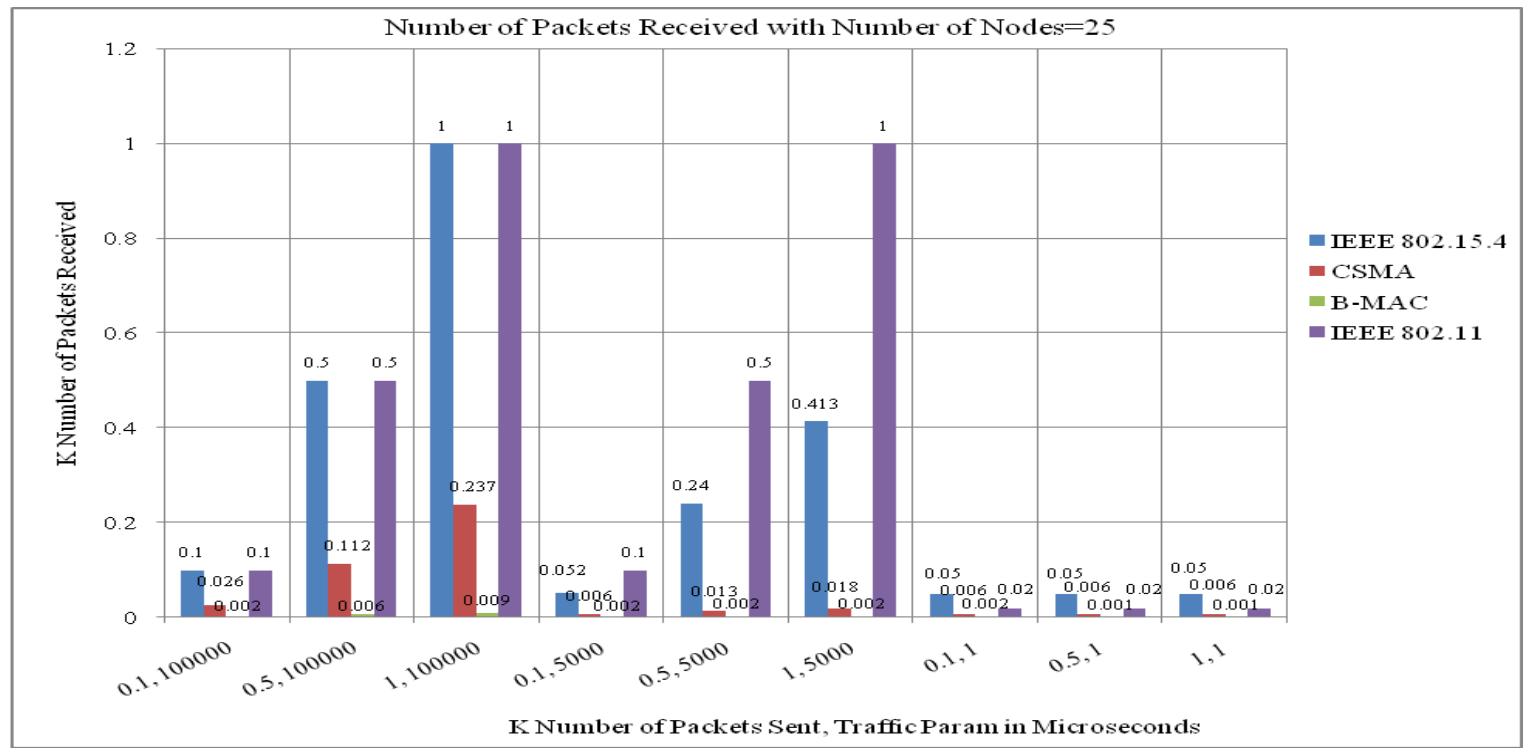

Fig. 7. K Number of Packets Received with each 4 MAC Layer Protocols at 25 Nodes 


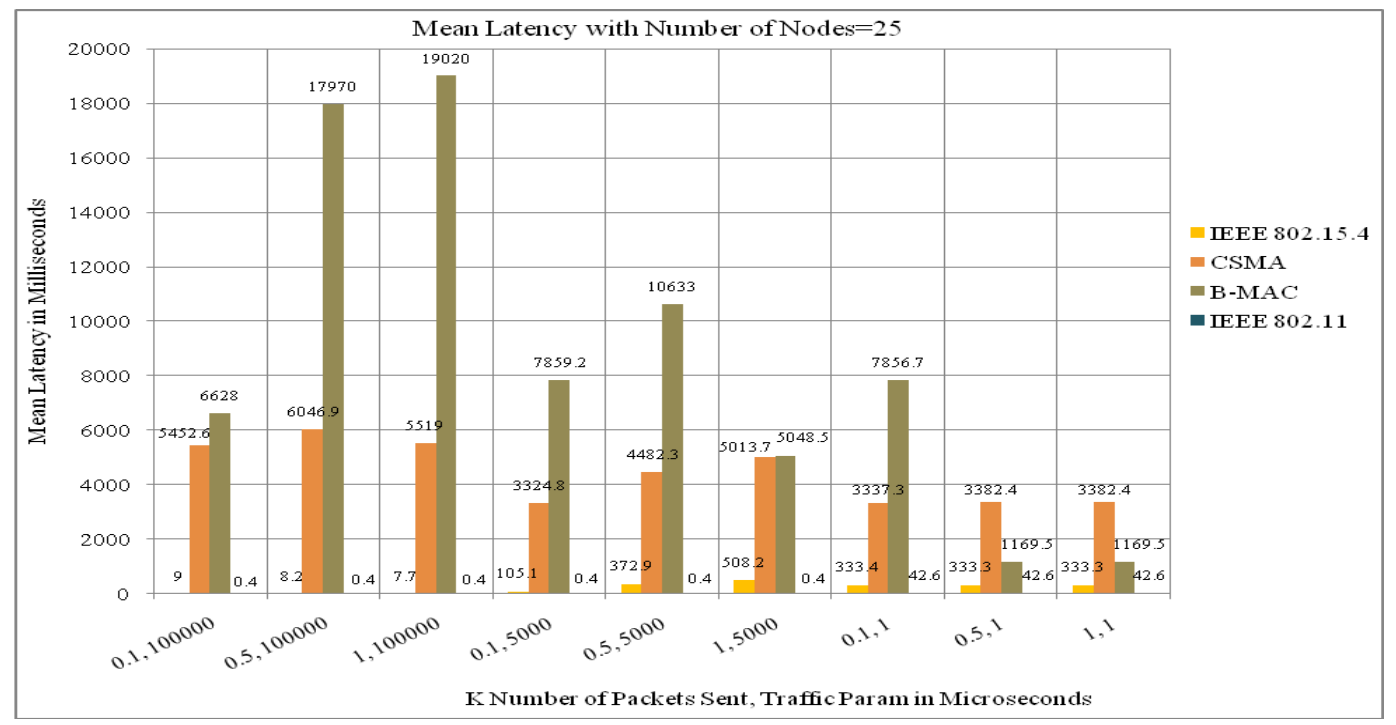

Fig. 8. Mean Latency in Milliseconds with each 4 MAC Layer Protocols at 25 Nodes

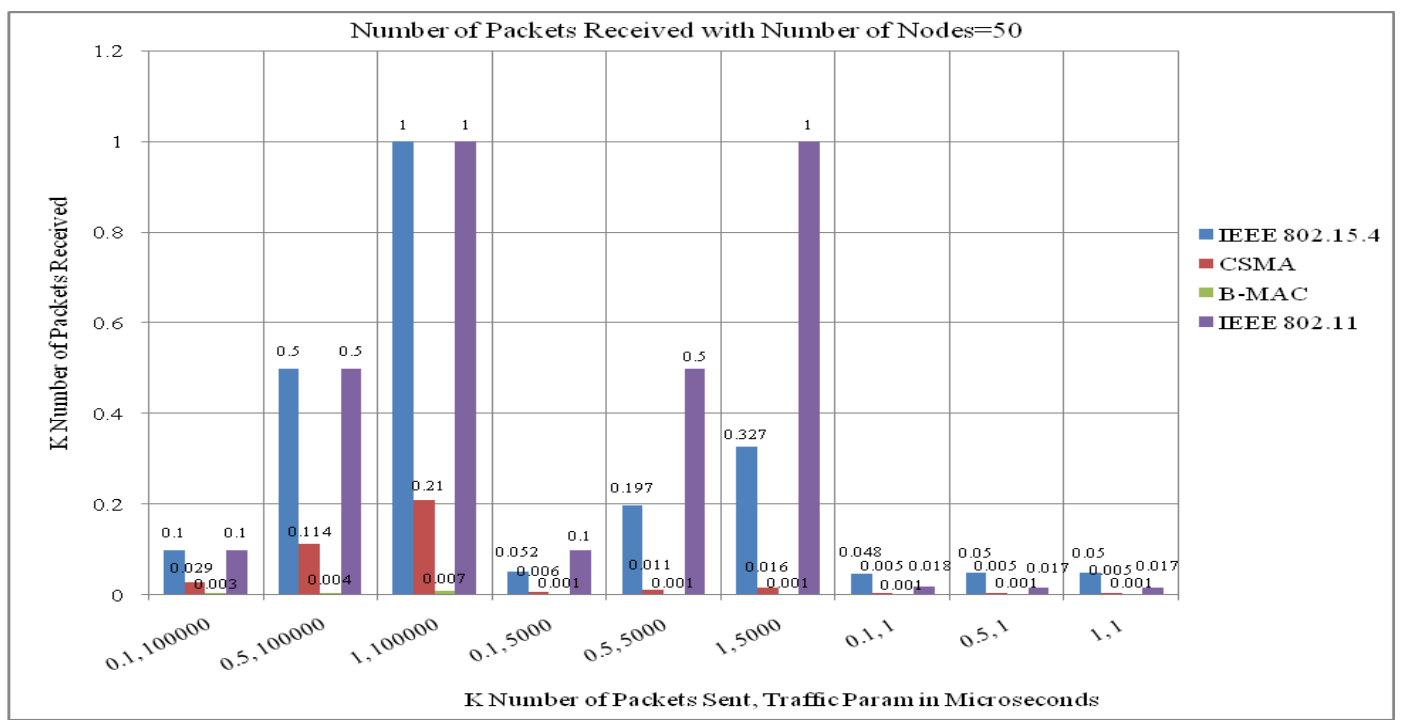

Fig. 9. K Number of Packets Received with each 4 MAC Layer Protocols at 50 Nodes

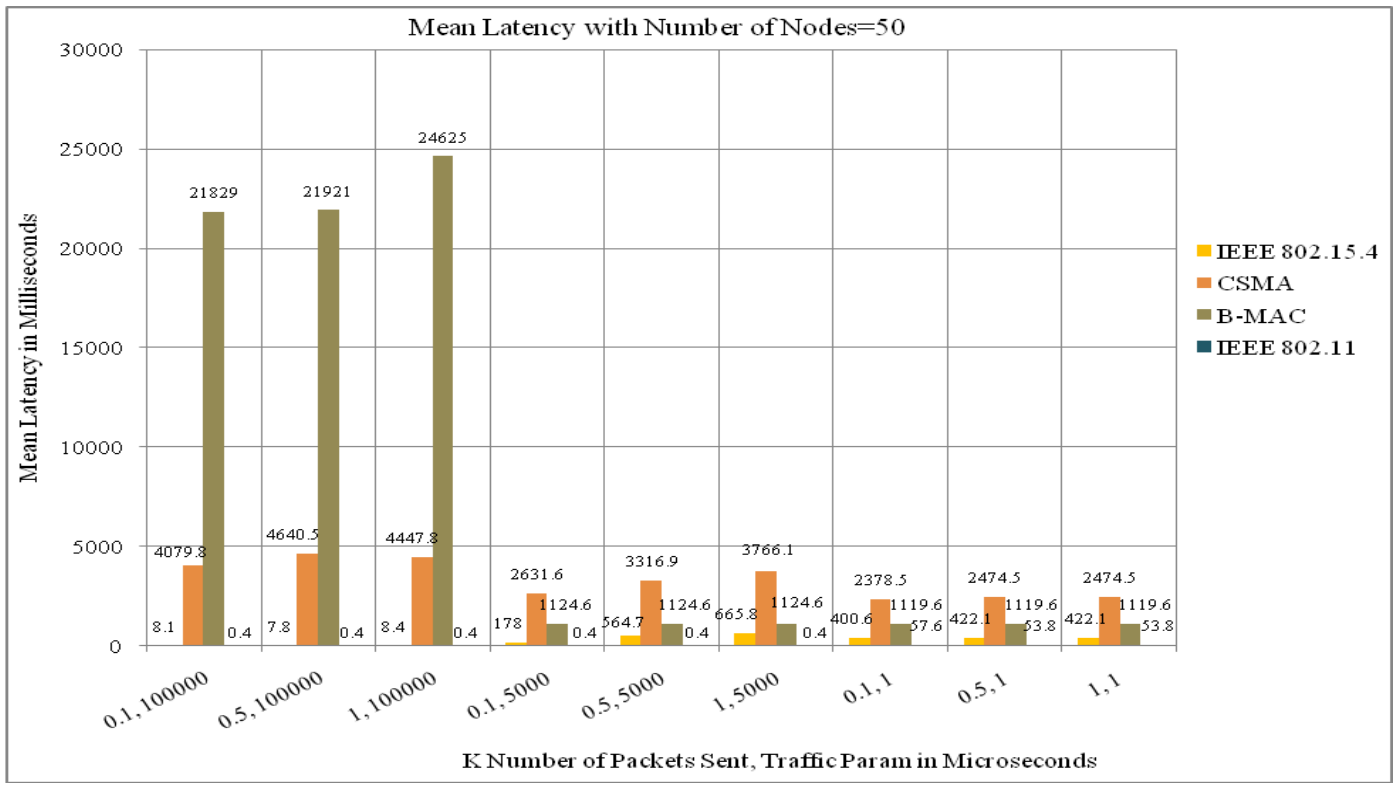

Fig. 10. Mean Latency in Milliseconds with each 4 MAC Layer Protocols at 50 Nodes 
Table 2. Performance Analysis of each 4 MAC Layer Protocols with different Traffic Param and 10 Nodes

\begin{tabular}{|c|c|c|c|}
\hline MAC Layer Protocols & Traffic Param $=100000 \mu s$ & Traffic Param $=5000 \mu s$ & Traffic Param $=1 \mu \mathrm{s}$ \\
\hline IEEE 802.15.4 (Mac802154) & $\begin{array}{c}\text { It performs well with average } \\
\text { packet delivery ratio of } 100 \% \text {. } \\
\text { Here the average mean latency is } \\
7.1 \mathrm{~ms} \text { which is good but greater } \\
\text { than IEEE } 802.11 \text {. }\end{array}$ & $\begin{array}{l}\text { The performance gets dropped as } \\
\text { traffic rate is increased. The } \\
\text { average packet delivery ratio is } \\
57.3 \% \text { and average mean } \\
\text { latency is } 83.26 \mathrm{~ms} \text {. }\end{array}$ & $\begin{array}{l}\text { With this much traffic rate, } \\
\text { performance is certainly dropped } \\
\text { further. Here average packet } \\
\text { delivery ratio is } 25.7666 \% \text { and } \\
\text { average mean latency is } 306.1 \mathrm{~ms} \text {. }\end{array}$ \\
\hline CSMA (csma) & $\begin{array}{l}\text { It performs worst. Here average } \\
\text { packet delivery ratio and latency } \\
\text { both are } 0 .\end{array}$ & Average packet delivery ratio is 0 & Average packet delivery ratio is 0 . \\
\hline B-MAC (BMacLayer) & $\begin{array}{l}\text { It performs better than CSMA but } \\
\text { still it has very less average packet } \\
\text { delivery ratio that is } 2.4 \% \text { and } \\
\text { high average mean latency that is } \\
9870.83 \mathrm{~ms} \text {. }\end{array}$ & $\begin{array}{l}\text { Average packet delivery ratio is } \\
0.9666 \% \text { and average mean } \\
\text { latency is } 7396.9 \mathrm{~ms} \text { better than } \\
\text { CSMA. }\end{array}$ & $\begin{array}{l}\text { Average packet delivery ratio is } \\
0.8666 \% \text { and average mean } \\
\text { latency is } 5408.43 \mathrm{~ms} \text { better than } \\
\text { CSMA. }\end{array}$ \\
\hline IEEE 802.11 (Mac80211) & $\begin{array}{c}\text { IEEE } 802.11 \text { performs well with } \\
\text { average packet delivery ratio of } \\
100 \% \text { and average mean latency of } \\
0.4 \mathrm{~ms} \text { which is less than IEEE } \\
802.15 .4 \text {. }\end{array}$ & $\begin{array}{c}\text { With an increase in the traffic rate } \\
\text { the average packet delivery ratio is } \\
\text { still } 100 \% \text { and latency is } 0.4 \mathrm{~ms} \text {. } \\
\text { Here it performs better than } \\
\text { others. }\end{array}$ & $\begin{array}{l}\text { With this much traffic rate, the } \\
\text { scheme gets collapsed before } \\
\text { IEEE } 802.15 .4 \text {. The average } \\
\text { packet delivery ratio is } 8.2333 \% \\
\text { and average mean latency is }\end{array}$ \\
\hline
\end{tabular}

Table 3. Performance Analysis of each 4 MAC Layer Protocols with different Traffic Param and 25 Nodes

\begin{tabular}{|c|c|c|c|}
\hline MAC Layer Protocols & Traffic Param $=100000 \mu s$ & Traffic Param $=5000 \mu \mathrm{s}$ & Traffic Param $=1 \mu \mathrm{s}$ \\
\hline IEEE 802.15.4 (Mac802154) & $\begin{array}{c}\text { It performs well with average } \\
\text { packet delivery ratio of } 100 \% \text { and } \\
\text { average mean latency of } 8.3 \mathrm{~ms} \\
\text { which is good but greater than } \\
\text { IEEE } 802.11 .\end{array}$ & $\begin{array}{c}\text { The performance gets dropped as } \\
\text { traffic rate is increased. The } \\
\text { average packet delivery ratio is } \\
47.1 \% \text { and average mean latency } \\
\text { is } 328.7 \mathrm{~ms} \text {. }\end{array}$ & $\begin{array}{l}\text { With this much traffic rate, } \\
\text { performance is dropped further. } \\
\text { Here average delivery ratio is } \\
21.6666 \% \text { and average mean } \\
\text { latency is } 333.3 \mathrm{~ms} \text {. }\end{array}$ \\
\hline CSMA (csma) & $\begin{array}{c}\text { As the number of nodes is } \\
\text { increased, CSMA performance } \\
\text { improves. The average packet } \\
\text { delivery ratio is } 24.0333 \% \text { and } \\
\text { average mean latency is } 5672.8 \mathrm{~ms} \text {. }\end{array}$ & $\begin{array}{c}\text { Average packet delivery ratio is } \\
3.4666 \% \text { and average mean } \\
\text { latency is } 4273.6 \mathrm{~ms} \text { which is too } \\
\text { high. }\end{array}$ & $\begin{array}{l}\text { Here average packet delivery ratio } \\
\text { is } 2.6 \% \text { and average mean latency } \\
\text { is } 3367.3 \mathrm{~ms} \text {. }\end{array}$ \\
\hline B-MAC (BMacLayer) & $\begin{array}{c}\text { Here average packet delivery ratio } \\
\text { is } 1.3666 \% \text { and average mean } \\
\text { latency is } 14539.3 \mathrm{~ms} \text { and it } \\
\text { performs worst. }\end{array}$ & $\begin{array}{c}\text { Average packet delivery ratio is } \\
0.8666 \% \text { and average mean } \\
\text { latency is } 7846.9 \mathrm{~ms} .\end{array}$ & $\begin{array}{c}\text { Here average packet delivery ratio } \\
\text { is } 0.7666 \% \text { and average mean } \\
\text { latency is } 3398.5 \mathrm{~ms} .\end{array}$ \\
\hline IEEE 802.11 (Mac80211) & $\begin{array}{c}\text { It performs well with average } \\
\text { packet delivery ratio of } 100 \% \text { and } \\
\text { average mean latency of } 0.4 \mathrm{~ms} \\
\text { which is less than IEEE } 802.15 .4\end{array}$ & $\begin{array}{c}\text { With the increase in traffic rate the } \\
\text { average packet delivery ratio is } \\
\text { still } 100 \% \text { and latency is } 0.4 \mathrm{~ms} . \\
\text { Here it performs better than other } \\
\text { protocols. }\end{array}$ & $\begin{array}{l}\text { With this much traffic rate, the } \\
\text { scheme gets collapsed before } \\
\text { IEEE } 802.15 .4 \text {. The packet } \\
\text { delivery ratio is } 8.6666 \% \text { and } \\
\text { average mean latency is } 42.6 \mathrm{~ms} \text {. }\end{array}$ \\
\hline
\end{tabular}

Table 4. Performance Analysis of each 4 MAC Layer Protocols with different Traffic Rate and 50 Nodes

\begin{tabular}{|c|c|c|c|}
\hline MAC Layer Protocols & Traffic Param=100000 $\mu$ s & Traffic Param $=5000 \mu \mathrm{s}$ & Traffic Param $=1 \mu \mathrm{s}$ \\
\hline IEEE 802.15.4 (Mac802154) & $\begin{array}{c}\text { It performs well with average } \\
\text { packet delivery ratio of } 100 \% \text { and } \\
\text { average mean latency of } 8.1 \mathrm{~ms} \\
\text { which is good but greater than } \\
\text { IEEE } 802.11 .\end{array}$ & $\begin{array}{l}\text { Performance gets dropped as } \\
\text { traffic rate is increased. The } \\
\text { average packet delivery ratio is } \\
41.366 \% \text { and average mean } \\
\text { latency is } 469.5 \mathrm{~ms} \text {. }\end{array}$ & $\begin{array}{c}\text { With this much traffic rate, } \\
\text { performance gets dropped further. } \\
\text { Here average packet delivery ratio } \\
\text { is } 21 \% \text { and average mean latency } \\
\text { is } 414.9 \mathrm{~ms} \text {. }\end{array}$ \\
\hline CSMA (csma) & $\begin{array}{c}\text { With an increase in nodes it } \\
\text { performs better than before with } \\
\text { an average packet delivery ratio of } \\
24.2666 \% \text { and average mean } \\
\text { latency of } 4389.3 \mathrm{~ms} . \\
\end{array}$ & $\begin{array}{l}\text { With an increase in traffic rate, } \\
\text { average packet delivery ratio is } \\
3.2666 \% \text { and average mean } \\
\text { latency is } 3238.2 \mathrm{~ms} \text {. }\end{array}$ & $\begin{array}{c}\text { Here average packet delivery ratio } \\
\text { is } 2.1666 \% \text { and average mean } \\
\text { latency is } 2442.5 \mathrm{~ms} \text {. }\end{array}$ \\
\hline B-MAC (BMacLayer) & $\begin{array}{l}\text { Here average packet delivery ratio } \\
\text { is } 1.5 \% \text { and average mean latency } \\
\text { is } 22791.6 \mathrm{~ms} \text {. }\end{array}$ & $\begin{array}{c}\text { Average packet delivery ratio is } \\
0.4333 \% \text { and average mean } \\
\text { latency is } 1124.6 \mathrm{~ms} .\end{array}$ & $\begin{array}{c}\text { Here average packet delivery ratio } \\
\text { is } 0.4333 \% \text { and average mean } \\
\text { latency is } 1119.6 \mathrm{~ms} .\end{array}$ \\
\hline IEEE 802.11 (Mac80211) & $\begin{array}{l}\text { It performs well with an average } \\
\text { delivery ratio of } 100 \% \text { and average } \\
\text { mean latency of } 0.4 \mathrm{~ms} \text { which is } \\
\text { again less than IEEE } 802.15 .4 .\end{array}$ & $\begin{array}{c}\text { With traffic rate increase the } \\
\text { average packet delivery ratio is } \\
100 \% \text { and latency is } 0.4 \mathrm{~ms} \text { which } \\
\text { is the same as before. Here it again } \\
\text { performs better than others. }\end{array}$ & $\begin{array}{l}\text { With this much traffic rate, the } \\
\text { scheme gets collapsed before } \\
\text { IEEE } 802.15 .4 \text {. The average } \\
\text { packet delivery ratio is } 7.7 \% \text { and } \\
\text { average mean latency is } 55 \mathrm{~ms} \text {. }\end{array}$ \\
\hline
\end{tabular}


By observing above scenario in Tables [2, 3, and 4] in the overall we can say that B-MAC protocol performs least amongst all. Then comes CSMA, which is better than B-MAC but not better than others, its packet delivery ratio is less and mean latency is high. Although, IEEE 802.11 performs best amongst all, both in terms of packet delivery ratio and latency but when the traffic rate is very high it is collapsed some time before IEEE 802.15.4. IEEE 802.15.4 shows good results but its performance matrices are still lower as compared to IEEE 802.11.

\section{CONCLUSIONS}

MAC layer protocol plays a major role in a WSN. In order to have an efficient WSN, an appropriate MAC layer protocol must be chosen. The decision should be made considering various factors such as number of nodes, mobility of the nodes, playground size and traffic rate.

The results presented in this paper, using OMNeT++ simulator \& MiXiM framework, show that IEEE 802.11 is the best suited MAC layer protocol in the considered experimental scenario. It dominates IEEE 802.15.4, CSMA and B-MAC MAC layer protocols in terms of both packet delivery ratio and mean latency. IEEE 802.11 gets collapsed some time before IEEE 802.15.4 in case of high traffic rate which is the only exception otherwise IEEE 802.11 is found to be the most appropriate. The performance ranking of MAC layer protocol is as follows. 1. IEEE 802.11, 2. IEEE 802.15.4, 3. CSMA, 4. B-MAC.

\section{REFERENCES}

[1] Madhav Bokare1, Anagha Ralegaonkar, "Wireless Sensor Network: A Promising Approach for Distributed Sensing Tasks", Excel Journal of Engineering Technology and Management Science, Vol. I, 2012, ISSN 2249-9032.

[2] Debnath Bhattacharyya, Tai-hoon Kim and Subhajit Pal, "A Comparative Study of Wireless Sensor Networks and Their Routing Protocols", MDPI Journal on Sensor, Vol. 10, 2010, pp. 10506-10523; doi: 10.3390/s101210506.

[3] Jianhui Zhang, Jiming Chen, Jialu Fan, Weiqiang Xu and Youxian Sun, "OMNeT++ based Simulation for Topology Control in Wireless Sensor Network: A Case Study", Proc of IEEE International Wireless Communications and Mobile Computing Conference Proceedings, IWCMC'08 I, Crete Island, Aug. 2008, pp. 1130-1134.

[4] Fei Yu, "A Survey of Wireless Sensor Network Simulation Tools", http://www.cse.wustl.edu/ jain/cse567-11/ftp/sensor.pdf [January 2014].

[5] K.Lakshmanarao, Ch.R. VinodKumar, K.Kanakavardhini, "Survey on Simulation Tools for Wireless Networks", International Journal of Engineering Research \& Technology (IJERT), Vol 2(10), 2013, pp 608-612.

[6] Jianliang Zheng and Myung J. Lee, "A Comprehensive Performance Study of IEEE 802.15.4", http://hackipedia.org/Hardware/Zigbee/A\%20Comprehens ive $\% 20$ Study $\% 200 f \% 20$ Ieee $\% 20802.15 .4 \% 20 \mathrm{And} \% 20 \mathrm{Zi}$ gbee\%20506.pdf [January 2014].

[7] Qicai Yu, Jianping Xing, Yan Zhou, Lei Zhou, "Performance Research and Simulation Analysis of the
MAC Layer Protocols in Wireless Sensor Networks", Proc. of IEEE International Communications and Networking Conference Proceedings, ChinaCom'06, Beijing, China, October. 2006, pp. 1-3.

[8] Chowdhury S.A., Islam M.T., Jaigirdar F.T., Faruqui M.R.U., Al Noor S., "Performance study and simulation analysis of CSMA and IEEE 802.11 in wireless sensor networks and limitations of IEEE 802.11", Proc. of IEEE International Computers and Information Technology Conference Proceedings, ICCIT '09, Dhaka, Bangladesh, December. 2009, pp. 431-436.

[9] Petrova M., Riihijarvi J., Mahonen P., Labella S., "Performance study of IEEE 802.15.4 using measurements and simulations", Proc. of IEEE International Wireless Communications and Networking Conference Proceedings, WCNC 2006, Las Vegas, April. 2006, pp. 487-492.

[10] Lamia Chaari, Lotfi Kamoun, "Performance Analysis Of IEEE 802.15.4/Zigbee Standard Under Real Time Constraints", International Journal of Computer Networks \& Communications (IJCNC), Vol.3, Sep 2011.

[11] Ahmad Abed Alhameed Alkhatib and Gurvinder Singh Baicher, "MAC Layer Overview for Wireless Sensor Networks", Proc. of IPCSIT International Computer Networks and Communication Systems Conference Proceedings, CNCS 2012, Vol.35, Singapore, 2012.

[12] Jeffrey Mehlman, "Cross-Layer Design: A Case for Standardization",

http://www.jeffreymehlman.com/EE359_Research_Projec t_Final_JAM.pdf [January 2014].

[13] Kurtis Kredo II and Prasant Mohapatra, "Medium Access Control in Wireless Sensor Networks", Preprint submitted to Computer Networks 29 June 2006 http://www.spirit.cs.ucdavis.edu/pubs/journal/SensorMac. pdf [January 2014].

[14] Aditi .P. Khadilkar and Nitin G. Palan, "Media Access Control Protocol for Mobile Sensor Network- Modelling Using OMNeT++ -MiXiM Network Simulator", International Journal of Computer Science and Information Technologies (IJCSIT), Vol. 2 (3), 2011, pp 1154-1159.

[15] Se-Young Yun, Yung Yi, Jinwoo Shin and Do Young Eun, "Optimal CSMA: A Survey ", Proc. of IEEE international Communication Systems Conference Proceedings, ICCS, Singapore, Nov. 2012, pp. 199-204.

[16] A.O Afolabi, S.O Olabiyisi, "Application of Routing Algorithm to Congestion Control in GSM Network", Proc. of Engineering World Congress Proceedings, Vol II, London, U.K, July. 2012.

[17] Rajesh Yadav, Shirshu Varma, N. Malaviya, "A Survey of MAC Protocols for Wireless Sensor Networks", UbiCC Journal, Volume 4, No. 3, Aug. 2009.

[18] Qiang Ni*, Lamia Romdhani, Thierry Turletti, "A Survey of QoS Enhancements for IEEE 802.11 Wireless LAN", Journal of Wireless Communications and Mobile Computing, Vol 4(5), 2004, pp.547-566.

[19] Anna Förster, "Implementation of the B-MAC Protocol for WSN in MiXiM", http://www.omnetworkshop.org/2011/uploads/slides/OMNeT_WS2011_S5_ C1_Foerster.pdf [January 2014].

[20] Himanshu Singh, Bhaskar Biswas, "Comparison of CSMA based MAC Protocols of Wireless Sensor Networks",http://arxiv.org/ftp/arxiv/papers/1205/1205.170 1.pdf [January 2014].

[21] Uroš Pešovic', Aleksandar Peulic', Žarko $\mathrm{C}^{`}$ uc`ej, "MAC protocols for wireless sensor networks", Elektrotehniški 
vestnik 75(1): Electrotechnical Review, Ljubljana, Slovenija, 2008, pp 50-55.

[22] E. Egea-Lo'pez, J. Vales-Alonso, A. S. Martı'nez-Sala, J. Garci'a-Haro, P. Pavo'n-Mariño, M. V. Bueno Delgado, "A wireless sensor networks MAC protocol for real-time applications", Pers Ubiquit Comput, DOI 10.1007/s00779-006-0111-6.

[23] Palan, Nitin G.; Khadilkar, Aditi.P ., "Media Access Control Protocol Modelling for Mobile Sensor NetworkUsing OMNeT++ -MiXiM Network Simulator", Proc. of IEEE International Sustainable Energy and Intelligent Systems Conference Proceedings, SEISCON 2011, Chennai, India, July. 2011, pp.641-644.

[24] OMNeT++, "OMNeT++ Documentation", http://www.omnetpp.org/ [January 2014].

[25] C. Mallanda, A. Suri, V. Kunchakarra, S.S. Iyengar, R. Kannan* and A. Durresi, "Simulating Wireless Sensor Networks with OMNeT++", http://www.csc.lsu.edu/sensor_web/sensor_simulator/Sens orSimulator-ACM-Computers.pdf [January 2014].

[26] OMNeT++ Documentation, "OMNeT++ User Guide", http://www.omnetpp.org/doc/omnetpp/UserGuide.pdf.

[27] MiXiM Documentation, http://mixim.sourceforge.net/ [January 2014].

[28] A. Kopke, M.Swigulski, K. Wessel, D. Willkomm, P. T. K. Haneveld, T. E. V. Parker, O. W. Visser, H. S. Lichte, and S. Valentin, "Simulating wireless and mobile networks in OMNeT++ the MiXiM vision", Proc. of 1st International OMNeT++ Workshop, Mar. 2008.

[29] NED Overview, "OMNeT++ User Manual", http://www.omnetpp.org/doc/omnetpp/manual/usman.htm l\#sec116 [January 2014].

[30] MiXiM, "MiXiM Network", http://sourceforge.net/apps/trac/mixim/wiki/HowToStart [January 2014].

[31] Pedro Jorge Teixeira Sousa, "Evaluation of Analytic Interference, Reception and Detection Modeling for IEEE 802.15.4 Networks with the MiXiM Omnet++ Framework", Master's Degree Project Stockholm, Sweden.

[32] MiXiM http://mixim.sourceforge.net/doc/MiXiM/doc/doxy/a0006 7.html\#details [January 2014].

[33] OMNeT++ Simulation Architecture, "OMNeT++ User Manual", http://omnetpp.org/doc/omnetpp/Manual.pdf [January 2014].

[34] András Varga, Rudolf Hornig, "An overview of the OMNeT++ simulation $\quad$ environment", http://omnetpp.org/doc/workshop2008/omnetpp40paper.pdf [January 2014].

[35] Malika BELKADI, Rachida AOUDJIT, Mehammed DAOUI, Mustapha LALAM, "Energy-efficient Secure Directed Diffusion Protocol for Wireless Sensor Networks", International Journal of Information Technology and Computer Science(IJITCS), 2013, pp-5056.

[36] Sanjeev Puri and S. P. Tripathi, "Dynamic High Level Cross Layer Security Mechanisms for Wireless Sensor Networks" International Journal of Information Technology and Computer Science (IJITCS), 2012, pp-4556.

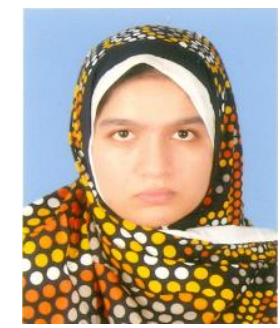

Hameeza Ahmed received the B.E degree in Computer and Information Systems from the NED University of Engineering and Technology, Pakistan in 2012. She is currently perusing her master's in Computer Architecture and Systems Design from the same university. Her research interests include wireless sensor network, parallel processing, distributed computing, pervasive computing, and computer architecture.

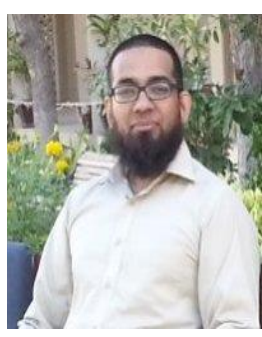

Muhammad Khurram obtained his Ph.D. in IC Design from Massey University, New Zealand in 2012. Currently, he is serving as associate professor in the Department of Computer and Information Engineering, NED University of Engineering \& Technology, Pakistan. His research interests are RF IC Design, Wireless Communication Systems, VLSI System Design, Embedded Systems and Systems Biology.

How to cite this paper: Hameeza Ahmed, Muhammad Khurram,"Performance Analysis of MAC Layer Protocols in Wireless Sensor Network", IJIEEB, vol.6, no.5, pp.44-52, 2014. DOI: 10.5815/ijieeb.2014.05.07 